\title{
A Conciliação e os Meios Alternativos de Solução de Conflitos no Império Brasileiro
}

\author{
Adriana Pereira Campos ${ }^{1}$ \\ Alexandre de Oliveira Bazilio de Souza ${ }^{1}$ \\ 1. Universidade Federal do Espírito Santo (UFES), Vitória, ES, Brasil. E-mail de contato: \\ acampos.vix@gmail.com
}

Eu considero um Juiz de Paz como um pai de família entre os seus filhos: persuade, concilia e faz assim desaparecer as contendas (palavras do deputado Baptista Pereira, na sessão de 21 de maio 1827)

\section{CONSIDERAÇÕES INICIAIS}

\begin{abstract}
A lentidão do processo é apontada como importante fator para a compreensão da crise que assola o Judiciário brasileiro. Não são raros os demandantes que passam sua vida nas amarras da Justiça pelo reconhecimento - ou execução forçada - de seu direito, muitas vezes frustrado ou, quando alcançado, disponível apenas a seus herdeiros. Não por acaso, o direito à duração razoável do processo foi inserido em nosso ordenamento jurídico por meio da Emenda Constitucional 45, aprovada ironicamente após quase 13 anos de tramitação (Lenza, 2005:1). Contudo, a mera previsão constitucional não foi suficiente para a solução do problema, uma vez que uma de suas principais causas não foi atacada: o assustador número de processos judiciais que tramitam no Brasil. Recente reportagem disponível no site do Superior Tribunal de Justiça (2012), ao comentar o relatório Justiça em Números de 2012, revelou existir, durante o ano de 2011, mais de 90 milhões de processos judiciais no Brasil, dos quais 26,2 milhões compunham no-

DADOS - Revista de Ciências Sociais, Rio de Janeiro, vol. 59, n-1, 2016, pp. 271 a 298.
\end{abstract}


vos casos abertos naquele ano: um gasto financeiro total de 50,4 bilhões de reais. A situação seria mais alarmante não fosse a alta taxa de produtividade, que atingiu quase 100\% em 2011 (foram 26 milhões de processos baixados). Em nossa mais alta corte, no mesmo ano, chegaram por via recursal 38.109 processos; no ano seguinte, esse valor saltou para 46.392 (Estatísticas do Supremo Tribunal Federal, 2012). No outro extremo das instâncias - nos juizados especiais -, 2011 viu circular quase 1 milhão de processos, que se somaram a outro milhão pendente (Justiça em Números, 2012:325).

Diante de tal cenário, muitas são as propostas para redução dessa imensa quantidade de processos abertos no país a cada ano, a exemplo dos meios alternativos de justiça. Hoje, essas iniciativas representam promissora opção para solução de conflitos, principalmente porque contam, via de regra, com importante participação das partes envolvidas. Dentre esses meios, destacam-se a mediação, a conciliação e a arbitragem, lembrados por Meneguin e Neves (2010) como maneiras distintas de apaziguar conflitos, e não formas de enfraquecimento do Judiciário. Dos três meios mencionados, a mediação ainda não possui previsão legal, enquanto a arbitragem é regulada pela Lei no 9.307 /96 e a conciliação possui previsão no próprio Código de Processo Civil (art. 125, IV). Na mediação, uma terceira pessoa (escolhida ou aceita pelas partes) atua por meio de conversas, por exemplo, no intuito de promover a solução da lide. A conciliação é bastante semelhante à mediação; a diferença reside no fato de ser promovida pelo próprio órgão judicial e de que sua tentativa é, muitas vezes, obrigatória por lei. Por fim, a arbitragem constitui-se em procedimento em que as partes escolhem um julgador estranho ao Judiciário, mas não interferem durante o processo decisório.

Seja por desconhecimento ou ausência de previsão normativa, é muito comum nos meios jurídicos que pouca ênfase seja dada a esses institutos. Como exceção, a conciliação talvez tenha recebido algum destaque, principalmente a partir da criação dos Juizados Especiais. Lorencini (2012:25) coloca a conciliação como principal pilar dos juizados alternativos e lembra seu atual exercício, inclusive, por pessoa diversa do juiz togado. Similarmente, Wagner Jr. (2008:682), ao citar a exposição de motivos do projeto de lei sobre mediação proposto pelo Instituto Brasileiro de Processo Civil e pela Escola Nacional de Magistratura, lembra que esta última característica dos atuais juizados foi herdada dos juizados de pequenas causas, criados pela 
Lei no 7.244/84. Vianna (1999:175) atribui a ênfase da conciliação existente nos citados juizados à tradição legal brasileira, identificável ainda na Constituição de 1824, que previa a existência de juízes de paz eleitos, a quem caberia a conciliação entre as partes e sem a qual nenhum processo poderia ter início.

O presente artigo busca discutir o juízo da conciliação no Brasil Império, apresentando a experiência histórica do instituto. As motivações de nossos legisladores, os mecanismos propostos e o modo como a conciliação funcionou no Brasil são apresentados ao longo do texto, no intuito de expor essa importante experiência de nosso direito pátrio. São discutidos ainda aspectos teóricos a respeito do fenômeno jurídico na passagem do Antigo Regime para a modernidade, posicionamentos conceituais sobre a natureza e o sentido da conciliação no ordenamento imperial e questões metodológicas referentes ao uso de fontes seriais e literárias.

\section{CONCILIAÇÃO PENSADA}

Os trabalhos atuais que abordam o fenômeno conciliatório no Império são bastante escassos. Ademais, seja por historiadores ou juristas, a discussão normalmente é feita de forma tangencial, já que os textos não tratam especificamente sobre o tema. Os historiadores dedicados ao assunto escrevem sobre a justiça de paz do Império. Nesse rol, há trabalhos como os de Motta (2013), Souza (2013), Campos (2011), Nascimento (2010), Vellasco (2003) e Flory (1981). De modo geral, esses textos buscam interpretar o significado da presença da magistratura leiga na administração da Justiça Imperial, seja em termos de descentralização política ou de participação popular na política. A conciliação aqui aparece como consequência do caráter local do juiz de paz, eleito nas freguesias. Já os juristas tratam da conciliação imperial quando inserem resumos históricos em suas monografias sobre meios alternativos de justiça. É o caso das produções de Ruiz e Gonçalves (2011), Watanabe (2011), Demarchi (2007) e Brandão Neto (2005). Nestes, encontramos as referências à conciliação oitocentista como argumento de cunho histórico para defender a ampliação - ou efetivação dos meios não judiciais de solução de conflitos. Não são, deste modo, estudos aprofundados sobre o tema e, via de regra, carecem de contextualização histórica.

Diferentemente dos textos jurídicos mencionados, a abordagem neste artigo sobre a conciliação no Império apresenta-se separada de sua rea- 
lidade atual, uma vez que objetiva o entendimento desse instituto jurídico em seu momento histórico. Por outro lado, também difere dos trabalhos dos historiadores citados, já que possui como objeto não a justiça de paz, mas a própria conciliação. Para isso, nesta primeira parte, é apresentada a forma como esse mecanismo jurídico foi concebido no Brasil, tomando como base a legislação da época, os discursos parlamentares e, sobretudo, livros de doutrina contemporâneos. Desse modo, seu objetivo é mostrar as concepções políticas e jurídicas envolvidas na interpretação da conciliação.

O apaziguamento entre as partes como fase preliminar processual, nas normas das primeiras décadas do século XIX, já tinha como meta a agilização do Judiciário brasileiro. $\mathrm{O}$ instituto constava na primeira carta constitucional do país. O art. 161 estabelecia a impossibilidade de iniciar-se qualquer processo no Império sem que anteriormente fosse aplicado o recurso da "reconciliação". Não era, contudo, o dispositivo novidade entre os brasileiros, pois a preocupação em constitucionalizar a matéria ocorrera ainda durante as reuniões das Cortes portuguesas entre 1821 e 1823. As Cortes Geraes e Extraordinárias da Nação Portuguesa (ACP) foram convocadas pela Junta Provisional escolhida após a eclosão do movimento insurgente do Porto, em 1820. Na ocasião, como se sabe, a família real se encontrava no Brasil. A assembleia diferia das reuniões anteriores das Cortes pela rejeição da representação por meio de ordens (clero, nobreza e povo), substituída pela igualdade entre todos os cidadãos. Esses critérios de eleição foram adotados sob influência da Constituição espanhola promulgada em Cádis na década anterior. O Brasil, como parte do reino, enviou representação escolhida em cada província (Vainfas, 2002:178).

Na sessão do dia 8 de fevereiro de 1822, entrou em pauta a conciliação obrigatória para o início de qualquer processo no Reino. O debate centrou-se em duas questões: a obrigatoriedade da conciliação e a titularidade da "função" (ACP, 1822:120). O deputado Guerreiro, no uso da palavra, observou que o "sistema constitucional" recomendava não entrar nesses detalhes circunstanciais. Em sua opinião, a Constituição devia apenas admitir a conciliação e delegar seu detalhamento à legislação ordinária. A discussão sobre as duas matérias, contudo, prosseguiu. Não se conseguiu admitir a conciliação separadamente de quem a conduziria. A reflexão sobre o responsável pela "função" acompanhou, com efeito, toda a contenda. 
Da leitura dos debates das Cortes portuguesas, constata-se certo orgulho em apontar a conciliação na cultura jurídica lusitana, pois D. João II, em 1481, teria antecipado, segundo alguns deputados, a preocupação em instituir "mediadores" com o objetivo de pacificar e "meter concórdia" nos desacordos. O encargo fora imaginado para "concertadores das demandas", de modo que se criou o regimento de 20 de janeiro de 1519 conservado em alguma medida no livro 3 das Ordenações T $20 \S 1$, que impôs aos juízes "o dever de compor as partes litigantes no comum das demandas". Por certo, não se pode afirmar que essa primeira forma de se pensar a conciliação tivesse o mesmo sentido imaginado pelos deputados portugueses. De fato, a partir do século XVIII, o Iluminismo alterou profundamente o panorama político europeu, com efeitos concretos sobre o direito da época. A ação política não mais se encontrava voltada para a imposição da Justiça, concentrando-se, antes, na eficácia do controle social. A Coroa buscou efetivar-se como o centro do poder, pondo fim à monarquia policentrada. Houve concreta preocupação com a reforma da Justiça, visando torná-la mais eficaz. Acima de tudo, incomodava à Coroa a tradição do ius comune, que determinava a precedência da doutrina sobre a lei. Para contornar o problema em Portugal, no ano de 1769 editou-se a Lei da Boa Razão, para consagrar as leis do Reino como a principal fonte de direito, relegando a doutrina, o costume e o Direito Romano à posição secundária da prática judiciária. Ao quadro geral de mudanças do direito integrava-se o movimento simultâneo de estruturação do Estado centralizado e desmantelamento dos poderes periféricos (Hespanha, 1994:498). Não obstante, os representantes das Cortes não hesitaram em utilizar essa memória - de forma quase retórica - no estabelecimento de instituto capaz de auxiliá-los na agilidade da justiça.

Com base em exemplos mais contemporâneos, Sr. Borges Carneiro divulgou aos seus pares os benefícios da conciliação entre os espanhóis: “Em mui pouco tempo só no juízo de 1ạ Instância de Madri se preveniram 220 demandas por estes juízos de conciliação" (ACP, 1822:121). Recomendava, porém, a eleição para a função em todos os conselhos, pois, dada sua experiência, juízes de fora e ordinários multiplicavam as demandas no lugar de colocar termo às dissensões. Considerava o encargo melhor entregue aos juízos de paz; caso contrário, o povo permaneceria oprimido. A matéria suscitava, portanto, posições contrárias e favoráveis. Os primeiros consideravam o instituto peça protelatória de acesso à Justiça; os últimos, economia processual. Recomendavam alguns a conciliação fora do âmbito judicial para o 
magistrado não se contaminar de preconcepções; os adversários da ideia argumentavam a capacidade e independência do Judiciário na matéria. Encerrada a discussão, propôs-se a votação da primeira parte do artigo contida nas seguintes palavras: "Nos mesmos negócios, de que tratam o artigo antecedente, os juízes de fora servirão de conciliadores entre as partes"; e ficou aprovada. Votou-se a alternativa de a doutrina permanecer omissa e decidiu-se que não, restando a seguinte redação: "Haverá juízos conciliatórios nas causas e pelo modo que a lei determinar".

As assembleias ibéricas do início do século XIX, tanto aquela de Cádis (1812) quanto as das Cortes de Lisboa (1821 a 1823), aspiravam cumprir propósitos liberais, ainda que se possa verificar o peso da tradição jurisdicional na forma dada a algum de seus dispositivos (Clavero, 2007:125). Resolutos em equacionar o acúmulo de demandas processuais, cujos efeitos resultavam na "opressão" dos povos, os deputados portugueses discutiram mais a titularidade da pacificação das querelas do que a validade do recurso conciliatório. Raras objeções se apresentaram ao esforço de entendimento entre as partes e o debate foi razoavelmente rápido. A decisão preliminar pela titularidade do juiz de fora, talvez, tenha-se devido à preocupação em preservar no âmbito do Judiciário o remédio legal proposto.

No dia 20 de agosto, nova decisão modificou a deliberação anterior. Colocado em votação o primeiro capítulo do título V relativo ao Poder Judicial, a mesa apresentou projeto cujo art. 146, alínea c, entregava a conciliação (item II) a juízes eletivos, escolhidos "pelos cidadãos diretamente no mesmo tempo e forma por que se elegem os vereadores das câmaras". A proposta não recebeu, desta vez, qualquer resistência e foi aprovada sem discussão. Na Constituição Portuguesa o assunto passou a constar dos artigos 181 e 195, este último redigido da seguinte maneira: "Haverá juízos de conciliação, nas causas e o modo que a lei determinar, exercitados pelos juízes eletivos" (ênfase no original).

Desde os primeiros dias de 1821 publicavam-se no país opiniões acerca das decisões tomadas em Portugal. Na pequena província do Espírito Santo, entre outros locais, panfletos rebeldes eram distribuídos. Um deles, do espírito-santense Manuel Pinto Ribeiro de Sampaio e intitulado "Verdade sem rebuço", acusava, em 10 de março de 1822, as Cortes de terem iludido o Brasil e de "intentarem colonizar povo livre" (Neves, 2003:329). As crescentes divergências, desde março de 1822, 
A Conciliação e os Meios Alternativos de Solução de Conflitos no Império...

circulavam por meio de manifestações e pugnavam pela criação de um legislativo no Brasil. Alguns propunham que o Conselho de Procuradores eleitos em cada província, reunido ainda em fevereiro de 1822, fosse reconhecido formalmente como parlamento. Outros, porém, como Hipólito da Costa, consideravam aquele Conselho insuficiente para representar a "vontade geral" e defendiam a existência de Cortes nos trópicos (ibidem:343).

Após rompimento com Portugal, reuniu-se a Constituinte Brasileira de 1823 por meio de eleição direta em cada termo do país. Adotavam-se, em princípio, as instruções liberais de Cádis e, posteriormente, a instrução do governo independente. Dentre os assuntos debatidos, a conciliação se afigurou como tema de reflexão dos constituintes. No entanto, os deputados brasileiros foram bem menos enfáticos que seus colegas lusitanos. Dentre três projetos propostos a respeito da administração das províncias, constava um, de autoria do deputado de Alagoas José de Souza e Mello, em que se previa a eleição de um "juiz do povo" escolhido entre pessoas "de conhecimentos, luzes e prudência, e que tenha a geral confiança, e amor dos povos". O art. 5o do projeto previa que sua função objetivava o "desafogo, e liberdade do povo, a quem este recorra nos casos de opressão [...]." A forma eletiva encontrava-se no art. 7으, cuja previsão era a escolha pelos "eleitores de paróquias, reunidos nas cabeças dos distritos e na forma da eleição dos deputados" (ACP, 1823:10). Não houve, naquela sessão, maiores debates com esclarecimentos ao leitor dos anais acerca da forma pretendida para o "desafogo". No projeto de Constituição apresentado à assembleia em 1 어 de setembro, não se encontra qualquer referência à conciliação. Havia apenas a previsão de juízes eletivos nos artigos 211 e 212, mas, segundo o texto, suas atribuições deveriam ser estabelecidas por futura legislação ordinária.

Em face do fechamento da Constituinte, Pedro I solicitou ao Conselho de Estado um projeto de Constituição para o Império do Brasil. Desta vez, a conciliação apareceu limpidamente, demarcada no art. 161 do seguinte modo: "Sem se fazer constar que se tem intentado o meio da reconciliação, não se começará processo algum". O artigo entregava o encargo aos juízes de paz eleitos. A redação final do texto de 1824 conservou tais preceitos. O projeto de lei que regularia a novíssima Justiça de Paz brasileira, entretanto, só seria proposto em 1826, com aprovação no ano seguinte por meio da lei de 15 de outubro de 1827. Já a norma que organizou as eleições do cargo entrou em vigor a partir da lei 
de 1ㅇ de outubro de 1828 (Campos e Vellasco, 2011:381). Isso significa que, por um bom tempo, não havia juízes de paz para promover a conciliação exigida pela Constituição. Desse modo, já em 1824, Pedro I determinou que todos os juízes e autoridades do Império deveriam observar o mandamento constitucional e promover a conciliação (Decreto de 17 de novembro de 1824). A decisão foi tomada a partir do recebimento de diversas reclamações, sobretudo de moradores afastados dos grandes centros, a quem estava sendo negada a abertura de processos por falta de conciliador. Na Câmara dos Deputados, a determinação foi interpretada como autoritarismo do imperador, um verdadeiro insulto à soberania do país. Tanto que o deputado Luiz Pedreira do Couto Ferraz propôs, em maio de 1826, a revogação da decisão, sob a alegação de violação do dispositivo constitucional que atrelava a conciliação aos juízes de paz (Motta, 2010:4).

As disputas políticas por que passava o legislativo brasileiro em seus primeiros anos de atuação foram bastante acirradas. A conciliação colocou-se no centro de uma delas, durante as discussões da lei orgânica dos juizados de paz, quando duas correntes formaram-se na Câmara. A primeira, da qual faziam parte Diogo Antônio Feijó (padre, futuro regente do Império, deputado por São Paulo) e Augusto Xavier de Carvalho (Paraíba do Norte), defendia que os juízes de paz deveriam ter somente atribuição de conciliadores, pois só esta estava prevista na Constituição. Já a segunda, da qual faziam parte Luiz Francisco de Paula Cavalcanti de Albuquerque (magistrado, deputado por Pernambuco), Bernardo Pereira de Vasconcellos (magistrado, deputado por Minas Gerais), João Chrysostomo de Oliveira Salgado (padre, deputado por São Paulo) e Miguel Calmon du Pin e Almeida (depois marquês de Abrantes, deputado pela Bahia), desejava que outras atividades fossem a eles concedidas. Mesmo nesse grupo, nenhum dos parlamentares queria que aos novos magistrados fosse dada larga alçada; pelo menos, não naquele momento. Cavalcanti, por exemplo, defendia que a nova lei regulasse apenas a conciliação e que os futuros Códigos Civil e Criminal tratassem de suas outras atribuições; Salgado e Vasconcellos defendiam que as outras atividades limitassem-se ao âmbito criminal; enquanto Calmon buscava o meio-termo: "não quero que os juízes de paz sejam reduzidos a juízes de vintena, mas também não quero que sejam considerados como magistrados em tudo e por tudo; pois não poderão satisfazer a tantas atribuições" (Brasil, 1889:279-283; Mendonça, 1889:7; 117-119). 
Em sua versão final, a Lei deu aos novos juízes de paz 14 atribuições além da conciliação, que incluíam julgamento de causas civis até o valor de 16 mil réis, julgamento de posturas, feitura do auto de corpo de delito, entre outras. Nos anos que se seguiram, os juízes de paz ganhariam atividades nas mais diversas áreas, entre as quais se destacaram as eleições e o julgamento de crimes. Ao longo do Império, o juizado de paz permaneceu ativo, apesar de suas incumbências terem variado bastante. Tal variação não era por acaso, já que refletia a política de centralização ou descentralização do governo central: uma vez que os juízes de paz eram membros eleitos da comunidade, uma maior gama de atividades traduzir-se-ia em menor poder na mão da Corte, e viceversa (Souza, 2013:9-11).

A possibilidade de maior descentralização do poder empolgava os partidários do liberalismo, enquanto outros políticos se mostravam mais receosos. Nas primeiras décadas do século XIX, o primeiro grupo conseguiu lograr sucesso em sua empreitada e o Brasil testemunhou um Judiciário em que juízes de paz e jurados decidiam grande parte das demandas. Com o passar dos anos, essa distribuição de poder alterou-se, principalmente com a concentração de praticamente toda jurisdição criminal nas mãos dos magistrados de carreira. Não obstante, em nenhum momento o Império aboliu a magistratura leiga e o final do período monárquico chegou a presenciar nova valoração dos juízes eletivos com a Reforma Judiciária de 1871 (Souza, 2013:17-21). Tais embates acabaram por repercutir na discussão sobre a própria natureza jurídica da conciliação e dos juízes de paz. O magistrado José Xavier Carvalho de Mendonça (1889:122), em obra sobre o tema, citava o advogado e doutrinador francês Frédéric Mourlon para concluir que a conciliação não era stricto sensu atividade jurisdicional, pois não envolvia julgamento. José Sales (1879:3, 47), outro doutrinador da época, chamava os juízes de paz de magistrados especiais, pois, apesar de terem jurisdição e administrarem a justiça, não possuíam vitaliciedade. Ao mesmo tempo, afirmava ter sido bastante oportuna sua escolha para a posição de conciliador, já que sua eleição refletiria a expressão da simpatia, respeito e consideração dos habitantes do distrito, o que facilitaria a retirada dos litigantes da "arena judicial" - expressão pelo ele mesmo usada. Alguns políticos mais radicais chegavam a defender que os juízes de paz não deveriam sequer ser chamados de magistrados. Foi o que disse o deputado conservador Samuel Wallace MacDowell, em sessão na Câmara no ano de 1883, ao explicar que o juiz de paz brasileiro, por ser este um cargo eletivo, não poderia ter 
ampla gama de atribuições. Para MacDowell, sua função deveria restringir-se à conciliação, pois tais juízes não tinham conhecimento profissional para julgar (Souza, 2013:108). A colocação do deputado possui forte conotação política, já que, ao tempo de sua fala, os juízes de paz brasileiros julgavam, havia mais de 60 anos, causas nos mais diferentes ramos do direito.

Ao mesmo tempo, a conciliação não era de forma alguma menosprezada pelos doutrinadores, que, contrariamente, exaltavam sua importância no direito ocidental. Alguns, como Mendonça (1889:123-125), reconheciam estar diante de um instituto muito antigo, cujos primórdios retraçavam à Grécia Antiga. José Marcelino Pereira de Vasconcelos (1862:6), em obra especialmente dedicada aos juízes de paz, aconselhava a apresentação às partes dos benefícios da composição amigável, mesmo com prejuízo para algumas delas. O jurista capixaba lembrava ainda que as demandas judiciais acarretavam grandes despesas (mesmo quando pequena quantia estava em questão), seus resultados eram duvidosos, seu tempo de conclusão podia levar muitos anos e, muitas vezes, nutriam ódio e inimizades. Ele também apontou a longa presença da conciliação na história jurídica, considerando-a verdadeiro preceito de justiça universal. De modo semelhante, Sales (1879:III-IV;46), em livro já referenciado, comentou que a observância das fórmulas do processo era mais imperativa na conciliação que no contencioso, já que era condição substancial dos processos. $\mathrm{O}$ autor afirmava que, apesar de todos os esforços dos juízes de paz para atentar aos anseios de seus jurisdicionados, as chicanas, a esperteza e até a falta de material de consulta podiam dificultar o exercício da "nobre tarefa", como a caracterizou. Este, aliás, foi um dos motivos que o levou a escrever seu livro, conforme explica na introdução do trabalho.

Como podemos ver, o funcionamento da conciliação e da Justiça de Paz foi objeto de inúmeros manuais escritos no período. Ainda em 1829, tanto Diogo Feijó como Bernardo de Vasconcellos publicaram textos nesse sentido (Souza, 2013:18). Já na segunda metade do século, aparece a citada obra de José Marcelino Vasconcellos (1862:5-11), na qual o autor descreve em minúcias os passos a serem observados no exercício de suas diferentes atribuições. Em relação à conciliação, ensinava que o juiz a quem a petição fosse apresentada deveria mandar citar o réu, de modo a ouvi-lo - bem como ao autor - na audiência, na qual ambos poderiam também apresentar documentos. Para realizar a composição das partes, ao magistrado era facultado dilatar o ato conci- 
A Conciliação e os Meios Alternativos de Solução de Conflitos no Império...

liatório para outro dia, se assim concordassem os querelantes. Havendo a conciliação, o juiz lavraria o termo; em caso contrário, apenas o escrivão redigiria uma simples declaração para constar no juízo contencioso.

O advogado Carlos Antônio Carneiro (1864:127-136) fez manual semelhante, em que enumera mais regras a serem seguidas durante o processo conciliatório. Com base no Código de Processo Criminal, especialmente nos artigos 58 a 60, ele recomendava que as audiências fossem realizadas com frequência mínima semanal e em local público. Na ausência de espaço apropriado, os encontros poderiam ocorrer na residência do juiz ou em qualquer outro lugar que este julgasse apropriado. Deveriam, sobretudo, ser públicas, de portas abertas, com a presença do escrivão e do oficial de justiça, em hora e dia certos, seu princípio anunciado pelo toque de campainha. Vários juízes de paz veicularam no Aurora Fluminense e no Diário do Rio de Janeiro, entre outros periódicos, anúncios com essas informações. Em 23 de dezembro de 1837, publicou-se o seguinte:

O cidadão Manoel Ferreira de Araujo Pitada, Juiz de Paz do 2o Distrito da candelária nesta Corte.

Faço saber que me acho exercendo as funções de Juiz de Paz deste Distrito, e que as audiências das sessões do Juízo, serão nos dias do costume, a saber: às 10 horas, e sendo feriado, ou dia Santo, no dia antecedente, e se de infração de Posturas nas Quartas feiras, na casa de minha residência rua do Rosário n. 25, aonde me acharão sempre pronto para os despachos. E para que chegue ao conhecimento de todos mandei passar o presente. Rio 22 de Dezembro de 1837.

E eu Pedro Peixoto de Albuquerque Sany, o escrevi. - Manoel Ferreira de Araujo Pitada (Diário do Rio de Janeiro, 1837).

Mendonça (1889:127-165), em obra já mencionada, sintetizou recomendações de vários autores e dedicou boa parte de seu texto à conciliação. Antônio Joaquim Ribas foi um dos doutrinadores por ele citados, cuja obra Consolidação das Leis Civis de 1879 dedica 17 comentários ao tema. O doutrinador fez elogios ao instituto, retraçando-o também até a antiguidade clássica. Não obstante, afirmava que, diferente da conciliação de outros tempos, aquela inaugurada na carta de 1824 não era apenas dever de honestidade (um bem poder fazer), mas necessidade - princípio herdado do modelo francês das leis civis. É por isso que considerava nulos todos os processos instaurados com tentativa de conciliação frustrada por revelia. O autor chegou a escrever mono- 
grafia dedicada exclusivamente ao assunto, intitulada "Da Conciliação no Cível e no Comercial", publicada na revista O Direito de 1874, volume 5 (Ribas, 1879:149-150; Roberto, 2012:23).

Nessas obras, assim como nos debates parlamentares, é possível perceber um corte bastante delineado entre as atividades consideradas propriamente jurisdicionais (ou seja, em que havia julgamento) e aquelas tidas como acessórias, a exemplo da conciliação. Ademais, apesar da referência histórica nesses textos ao instituto análogo utilizado no Antigo Regime - ou mesmo na Grécia Clássica -, as regras de funcionamento e a natureza jurídica deste não são replicadas na conciliação criada no Império, já que esta possui como espelho o legalismo criado a partir da experiência francesa. As citações aos períodos anteriores funcionam, assim, não como modelo, mas como argumentos políticos e retóricos para a adoção de modos alternativos e mais céleres de solução de conflitos. A expressão utilizada não é anacrônica na medida em que há uma continuidade, a partir da modernidade, na forma como o Estado detém o monopólio jurisdicional e determina, segundo regras dele emanadas, as possibilidades de seu afastamento. Nesse contexto, a figura do juiz de paz aparece de forma privilegiada, uma vez que detinha a característica suprajurídica que poderia aumentar as chances de efetivar a conciliação, a saber, sua proximidade dos jurisdicionados, possibilitada tanto pela investidura eleitoral do cargo quanto pela atuação nas freguesias ou distritos de paz. Juízes de direito e municipais, em contraposição, tinham área de jurisdição muito maior: comarca e município (ou termo) respectivamente, além de nomeação direta pelo governo.

A partir dessas colocações, podemos passar para a segunda metade deste artigo, em que são analisadas as possibilidades fáticas de realização de conciliação no Juízo de Paz. Para isso, são utilizados como fonte textos literários, jornais e documentos oficiais, como relatórios de governo e ofícios elaborados pelos magistrados eletivos.

\section{CONCILIAÇÃO PRATICADA}

A sala de audiência encontra-se na casa do próprio juiz de paz; na parte central do cômodo está a mesa, cheia de papéis em cima; em sua volta, cadeiras. João Rodrigues, o magistrado eleito, veste uma calça branca, casaco, chinelas verdes e não porta gravata. Enquanto prepara-se para o início dos trabalhos, percebe que seu escrivão está atrasado. "Sem 
A Conciliação e os Meios Alternativos de Solução de Conflitos no Império...

dúvida, está na venda do Manuel do Coqueiro", pensa. Logo em seguida, alguém bate à porta: era um preto que trazia um cacho de bananas e uma carta de Manuel André de Sapiruruca, um de seus jurisdicionados. João Rodrigues dá um vintém para o negro como agradecimento pela entrega e este se vai. Novamente, alguém bate à porta: desta vez era o escrivão, que logo toma assento à mesa para dar início às sessões.

O juiz toca a campainha e convida aqueles que aguardam no terreiro para entrar. São lavradores vestidos como roceiros, trajando jaqueta de chita, chapéu de palha, calças brancas de ganga, de tamancos, descalços ou com sapatos. Com todos à sala, o juiz declara aberta a audiência e vários presentes entregam seus requerimentos. Assim que autorizado, o escrivão lê o primeiro deles:

Diz Inácio José, natural desta freguesia e casado com Josefa Joaquina, sua mulher na face da Igreja, que precisa que Vossa Senhoria mande a Gregório degradado para fora da terra, pois teve o atrevimento de dar uma umbigada ${ }^{1}$ em sua mulher, na encruzilhada do Pau-Grande, que quase a fez abortar, a qual umbigada fez cair a dita sua mulher de pernas para o ar. Portanto pede a Vossa Senhoria mande o dito Gregório degradado para Angola. E.R.M. ${ }^{2}$ (Pena, 1997:8).

Após a leitura, Gregório é questionando sobre a veracidade do relato, negando-o por completo. A sra. Josefa sugere mostrar as marcas na barriga para provar o ocorrido, mas o juiz diz não ser necessário. Ela completa que aquela não tinha sido a primeira vez que fora atacada pelo demandado, e que só não tinha feito denúncia antes por receio de perturbar o marido.

Diante do impasse, o juiz lembra ao demandante que o crime de dar umbigadas não estava tipificado no Código, mas advertiu Gregório que, se continuasse a perturbar dona Josefa, iria mandar colocá-lo na cadeia. E foi feita a conciliação.

O escrivão prossegue para ler o próximo requerimento:

Diz João de Sampaio que, sendo ele senhor absoluto de um leitão que teve a porca mais velha da casa, aconteceu que o dito acima referido leitão furasse a cerca do Sr. Tomás pela parte de trás, e com a sem-cerimônia que tem todo o porco, fossasse a horta do mesmo senhor. Vou a respeito de dizer, Sr. Juiz, que o leitão, carece agora advertir, não tem culpa, porque nunca vi um porco pensar como um cão, que é outra qualidade de alimária e que pensa às vezes como um homem. Para V.S. ${ }^{\text {na }}$ ão 
pensar que minto, lhe conto uma história: a minha cadela Tróia, aquela mesma que escapou de morder a V.S. - naquela noite, depois que lhe dei uma tunda nunca mais comeu na cuia com os pequenos. Mas vou a respeito de dizer que o Sr. Tomás não tem razão em querer ficar com o leitão só porque comeu três ou quatro cabeças de nabo. Assim, peço a V.S. que mande entregar-me o leitão. E.R.M. (Pena, 1997:9).

Ao ser indagado se o descrito é verdade, o sr. Tomás responde positivamente, mas afirma que o leitão agora lhe pertence. O sr. Sampaio afirma ser aquilo um absurdo e tenta agarrar o porco que estava no colo do demandado. No meio do embate, o juiz pede para o escrivão chamar o oficial de justiça, o que faz as partes cessarem a briga. O magistrado propõe que o leitão seja dado para uma terceira pessoa, com o que as partes concordam. A oferta é então feita ao juiz, que prontamente aceita: "gosto tanto de porco com ervilha" - declara. E as partes saem conciliadas.

Finalmente, o escrivão inicia a leitura do último requerimento do dia:

Diz Francisco Antônio, natural de Portugal, porém brasileiro, que tendo ele casado com Rosa de Jesus, trouxe esta por dote uma égua. Ora, acontecendo ter a égua de minha mulher um filho, o meu vizinho José da Silva diz que é dele, só porque o dito filho da égua de minha mulher saiu malhado como o seu cavalo. Ora, como os filhos pertencem às mães, e a prova disto é que a minha escrava Maria tem um filho que é meu, peço a V.S. - mande o dito meu vizinho entregar-me o filho da égua que é de minha mulher (Pena, 1997:10).

O juiz então pergunta ao senhor José se o potro estava em sua posse, $\mathrm{o}$ que é confirmado. O demandado alega, contudo, que os filhos devem pertencer ao pai. O magistrado imediatamente diz não ser esse o caso e ordena que o animal seja entregue à mãe. O demandado protesta e diz que irá recorrer ao presidente de província. Impaciente, o juiz ameaça convocar o demandado como soldado da guarda nacional caso insistisse com a demanda, o que finalmente o faz recuar. A conciliação é assim feita e João Rodrigues declara encerrada a sessão.

As audiências relatadas fazem parte da famosa peça de Martins Pena, O Juiz de Paz na Roça, encenada pela primeira vez no Rio de Janeiro em 4 de outubro de 1838. Nela, o mundo judicial é retratado com riqueza de detalhes. Isso talvez se deva ao fato de o autor ter tido, desde pequeno, contato com o Judiciário, já que seu pai foi juiz da freguesia de Santa 
Rita e desembargador (Souza, 2013:21-23). Possivelmente por isso, mesmo ficcional, a narração inclui diversos ritos previstos pela legislação, tais como a audiência na casa do próprio juiz na indisponibilidade de lugar público apropriado; o toque de campainha para iniciá-la; a presença do escrivão e do oficial de justiça; a aplicação pelo juiz de paz de diferentes meios para alcançar a conciliação, como perguntas e recomendações às partes. É verdade que este último ponto foi abordado de forma bastante satírica pelo autor, já que os querelantes aparecem coagidos a se conciliarem. Do mesmo modo, outras práticas condenáveis são retratadas nas cenas, como o recebimento de presentes, o autoritarismo, o desconhecimento da legislação. Os relatos, porém, não devem ser enxergados nem como pura ficção teatral nem como exposição de fatos severamente fidedignos, mas como exageros artísticos. É muito provável que os milhares de juízes de paz que atuaram no Império realizassem as mais diversas práticas ilícitas (culposa ou dolosamente). Havia aspectos da legislação que podiam ser obscuros até para os mais expertos doutrinadores, a exemplo do limite dos meios pacíficos de que o juiz de paz poderia lançar mão para alcançar a conciliação. Desse modo, comicamente ou não, conciliações ocorriam pelo Brasil, possivelmente, à revelia da vontade das partes, numa atitude pragmática para alcançar o que teleologicamente previa a Constituição.

A peça de Pena (1997) ficou tão famosa nas arenas políticas do Império que era constantemente citada para referenciar qualquer agente público corrupto, incompetente ou dependente. Na sessão de 15 de junho de 1861 da Câmara dos Deputados, por exemplo, durante as discussões das eleições do segundo distrito de Alagoas, exatamente no momento em que alguns deputados debatiam o significado da palavra pretexto, Cristiano Ottoni afirmou que qualquer juiz de paz da roça sabia que pretexto significava motivo falso, alegado para esconder o verdadeiro. Já o deputado Costa Pinto, durante as discussões sobre a eleição do primeiro distrito de São Paulo na sessão de 8 de maio do mesmo ano, usou a expressão para explicar que muitas vezes advogados astutos faziam chicanas para atrapalhar o trabalho dos pobres juízes de paz da roça.

Referência ao magistrado eleito apareceu também nos textos satíricos de João Nepomuceno da Silva (1864). No poema, o autor zombava do juiz de paz de seu distrito, por sua ignorância e arrogância. O interessante é que o zombador, logo no início do texto, declarava que o juiz recebia a todos, mesmo de ceroulas. Entre seus defeitos, certamente a ne- 
gação da jurisdição não figuraria, indício de que, assim como João Rodrigues, também este tentava a todo custo conciliar as partes.

No livro A Carteira de Meu Tio de Joaquim Macedo, também encontramos alusão ao juiz de paz da roça, quando um dos personagens sugeriu abolir o júri por portaria:

Não seria o primeiro nó gordo que por tal modo se desatasse no Brasil. Graças à Providência nós temos tido por ministros de estado na nossa terra cada Alexandre Magno do tamanho assim! Não é brinquedo, ministros, como o Juiz de Paz da Roça que revoga a Constituição por uma vez somente, contamos apenas um ou outro; mas que revogam a pobre defunta viva, somente por muitas vezes, isso é um gosto: conta-se às dúzias! (1855:136).

De fato, muitas tibiezas dos juízes de paz advinham das incompletudes da lei, ainda mais nos primeiros anos. Outras vezes, acompanhar as mudanças legislativas exigia a atualização muito rápida para a época. O juiz de paz da freguesia de São José (Rio de Janeiro), o senhor Manoel Theodoro Azambuja, por exemplo, publicou edital com diversas orientações para evitar "delongas" processuais (Diário do Rio de Janeiro, 1/3/1830). Nas instruções constava que não se admitiria procurador nas conciliações, a não ser em caso de impossibilidade da parte de comparecer pessoalmente à audiência, além de procedimentos por escrito para citação de testemunhas, certidões, entre outros. Resolvia, assim, o juiz de paz carioca, dúvidas entre aqueles magistrados eleitos a respeito dos encaminhamentos processuais para a conciliação.

De todo modo, a instituição fora recebida com expectativa por parte da sociedade brasileira. Ao analisar os processos judiciais de algumas freguesias do Rio de Janeiro, notamos que as conciliações alcançavam frequência alta, variando entre $9 \%$ e $64 \%$, conforme se vê na tabela a seguir:

É importante salientar que esses dados devem ser analisados com cuidado, já que foram construídos a partir da análise individual de cada processo disponível no fundo dos juizados de paz guardados no Arquivo Nacional. É esperado que muitos processos sejam faltosos, ou que sua classificação (realizada durante a construção do banco de dados organizada pelo próprio Arquivo) apresente falhas. Por outro lado, é possível comparar esses valores com as informações fornecidas 
A Conciliação e os Meios Alternativos de Solução de Conflitos no Império...

Tabela 1

Conciliações em alguns Juízos de Paz do Rio de Janeiro

(1830-1899)

\begin{tabular}{l|cc|c|c}
\hline \multirow{2}{*}{ Freguesia } & \multicolumn{2}{|c|}{ Conciliações } & \multirow{2}{*}{ Total de Ações } & Período \\
\cline { 2 - 3 } & $\mathbf{N}$ & $\mathbf{\%}$ & & $1851-1887$ \\
Campo Grande & 49 & 64 & 77 & $1830-1890$ \\
Candelária & 248 & 55 & 454 & $1874-1890$ \\
Espírito Santo & 37 & 52 & 71 & $1831-1896$ \\
Glória & 25 & 7 & 370 & $1863-1896$ \\
Inhaúma & 34 & 43 & 80 & $1873-1899$ \\
Santo Antônio & 6 & 21 & 29 & $1833-1890$ \\
São José & 1 & 9 & 11 & \\
\hline
\end{tabular}

Fonte: Acervo Judiciário (1830-1899).

pelos periódicos de época. A conciliação evocada pelo Aurora Fluminense, de 22 de fevereiro de 1830, em sua quarta página, registrava, em tom elogioso, que seu efeito já se enunciava em freguesias próximas à Corte. Segundo o jornal, o exercício da conciliação afugentara o "gênio da chicana". Na Paraíba (do Sul), certo escrivão queixava- se de que "depois da criação dos juízes de paz, há dias em que se não faz hum real no cartório". A forma genérica da redação demonstra a simpatia do redator pelo instituto. O Aurora Fluminense informava ainda, em 29 de março de 1830, que "[...] Nas Freguesias da Cidade, de que temos notícia; das causas propostas mais da metade tem sido logo concluída por meio da conciliação [...]". A empatia do periódico com a pacificação das partes se revelava na razão atribuída ao seu sucesso. Consoante o noticioso era a "[...] prudência, as boas maneiras de que se servem os Srs. Juízes de Paz, tem influído poderosamente se obter tão excelente resultado [...]". De informações expostas pelo Aurora Fluminense (17/5/1830), obtém-se a Tabela 2 com dados extremamente positivos, com taxas de conciliação entre $53 \%$ e $74 \%$ para diversas freguesias cariocas naquele ano:

Os dados do periódico acerca da conciliação não se resumiam ao Rio de Janeiro. Outra notícia dada pelo jornal (30/12/1830) apresenta quadro igualmente favorável no termo da Vila do Príncipe, em São Paulo. Entre 5 de fevereiro de 1829 e 30 de outubro de 1830, as conciliações somavam 111, não se pacificando somente 49 .

Podemos ainda verificar o ritmo das conciliações por meio de consulta aos ofícios dos próprios juízes de paz, com dados potencialmente mais

DADOS - Revista de Ciências Sociais, Rio de Janeiro, vol. 59, n 1, 2016 
Tabela 2

Conciliações em algumas Freguesias do Rio de Janeiro

(1830)

\begin{tabular}{l|cc|cc}
\hline \multirow{2}{*}{ Freguesia } & \multicolumn{2}{|c|}{ Reconciliação Efetuada } & \multicolumn{2}{c}{ Reconciliação Não Efetuada } \\
\cline { 2 - 5 } & $\mathbf{N}$ & $\mathbf{\%}$ & $\mathbf{N}$ & \% \\
\hline São José & 51 & 64 & 29 & 36 \\
Santa Rita & 51 & 74 & 18 & 26 \\
S. Anna & 48 & 70 & 21 & 30 \\
Candelária & 47 & 53 & 41 & 47 \\
Sacramento & 77 & 62 & 47 & 38 \\
\hline Total & $\mathbf{2 7 4}$ & $\mathbf{6 4}$ & $\mathbf{1 5 6}$ & $\mathbf{3 6}$ \\
\hline
\end{tabular}

Fonte: Aurora Fluminense (1830)

confiáveis. Tais ofícios eram encaminhados para o presidente de província, que organizava as estatísticas a serem enviadas para o governo central. Na página seguinte a seu despacho, o juiz de paz anexava seu mapa de conciliação, a partir de um modelo padrão, em que eram separadas as conciliações intentadas das verificadas. Para aquelas não logradas, eram discriminadas as não ocorridas por revelia ou com a presença das partes. No Arquivo Público do Estado de São Paulo foram encontrados 67 ofícios dessa natureza enviados entre os anos de 1854 e 1885, 21 dos quais foram utilizados na confecção da Tabela 3 a seguir:

Os dados de São Paulo, assim como os do Rio de Janeiro, mostram que grande parte dos processos encerrava-se na própria conciliação. Ao observar aquelas não verificadas, é possível notar que a maioria se deu por revelia. Combinadas, essas informações mostram o grande potencial conciliatório dos magistrados de paz, cuja falha muitas vezes se dava porque o réu não estava presente. Os três casos apresentados na Tabela 3 em que a taxa de conciliação ficou abaixou dos 10\% (Nossa Senhora do Ó e Sé em 1854; Brás em 1861) teriam valores muito mais altos se desconsiderados os casos de revelia. Para a freguesia de Nossa Senhora do Ó, nenhum processo seria ali contabilizado, já que a única conciliação intentada foi aquela não verificada por revelia. Na Sé, descontadas aquelas em que uma das partes se ausentou, a taxa de conciliação subiria de $8 \%$ para $25 \%$. Já no Brás, a taxa de conciliação continuaria zerada, porém num universo de apenas 6 processos. Feito o mesmo cálculo para Juqueri em 1854, a taxa ali alcançaria os $100 \%$. Como se pode observar, a revelia alcançou cifras bastante altas em praticamente todas as freguesias analisadas. Tinham razão, portanto, os legisladores 
A Conciliação e os Meios Alternativos de Solução de Conflitos no Império...

Tabela 3

Conciliações em alguns Juízos de Paz de São Paulo

(1854-1863)

\begin{tabular}{|c|c|c|c|c|c|c|c|c|}
\hline \multirow{2}{*}{ Freguesia } & \multirow{2}{*}{ Ano } & \multirow{2}{*}{ Intentada } & \multicolumn{2}{|c|}{ Verificada } & \multicolumn{2}{|c|}{ Revelia } & \multicolumn{2}{|c|}{ No Juízo } \\
\hline & & & $\mathbf{N}$ & $\%$ & $\mathbf{N}$ & $\%$ & $\mathbf{N}$ & $\%$ \\
\hline Conceição de Guarulhos & 1854 & 14 & 3 & 21 & 5 & 36 & 6 & 43 \\
\hline Juqueri & 1854 & 32 & 24 & 75 & 8 & 25 & 0 & 0 \\
\hline Nossa Senhora do Ó & 1854 & 1 & 0 & 0 & 1 & 100 & 0 & 0 \\
\hline Santa Ifigênia & 1854 & 51 & 11 & 22 & 27 & 53 & 13 & 25 \\
\hline Sé & 1854 & 40 & 3 & 8 & 28 & 70 & 9 & 23 \\
\hline Itapecerica & 1854 & 29 & 17 & 59 & 6 & 21 & 6 & 21 \\
\hline Sé - Distrito do Sul & 1854 & 45 & 17 & 38 & 10 & 22 & 18 & 40 \\
\hline Santa Ifigênia & 1855 & 43 & 12 & 28 & 22 & 51 & 9 & 21 \\
\hline Brás & 1855 & 12 & 9 & 75 & 2 & 17 & 1 & 8 \\
\hline Brás & 1856 & 9 & 2 & 22 & 3 & 33 & 4 & 45 \\
\hline Juqueri & 1856 & 16 & 8 & 50 & 6 & 38 & 2 & 12 \\
\hline Conceição de Guarulhos & 1856 & 5 & 1 & 20 & 2 & 40 & 2 & 40 \\
\hline São Bernardo & 1857 & 5 & 2 & 40 & 2 & 40 & 1 & 20 \\
\hline Santa Ifigênia & 1857 & 38 & 21 & 55 & 11 & 29 & 6 & 16 \\
\hline Sé - Distrito do Sul & 1857 & 35 & 4 & 11 & 21 & 60 & 10 & 29 \\
\hline Sé - Distrito do Norte & 1857 & 52 & 12 & 23 & 41 & 79 & 1 & 2 \\
\hline Santa Ifigênia & 1859 & 26 & 12 & 46 & 13 & 50 & 1 & 4 \\
\hline Nossa Senhora do Ó & 1859 & 2 & 2 & 100 & 0 & 0 & 0 & 0 \\
\hline Nossa Senhora da Penha de França & 1859 & 2 & 1 & 50 & 0 & 0 & 1 & 50 \\
\hline Brás & 1861 & 11 & 0 & 0 & 5 & 45 & 6 & 55 \\
\hline Santa Ifigênia & 1863 & 71 & 18 & 25 & 25 & 35 & 28 & 40 \\
\hline
\end{tabular}

Fonte: Ofícios diversos (1854-1863).

quando se preocupavam em obrigar a presença na audiência de conciliação.

Finalmente, foram consultadas as estatísticas da conciliação confeccionadas pelo Ministério da Justiça, que utilizava dados enviados das províncias. Ressalta-se, todavia, que essas informações apresentam muitas lacunas, como mesmo atestou o ministro Francisco Diogo Pereira Vasconcellos em seu relatório do ano de 1857 (Brasil, 1857:1-15). A Tabela 4 mostra o mapa construído naquele ano.

Apesar de sua incompletude, os dados condizem com as informações anteriores, indício de que muito provavelmente refletem a realidade

DADOS - Revista de Ciências Sociais, Rio de Janeiro, vol. 59, nำ 1, 2016 
Tabela 4

Mapa de Conciliações - Império (1857)

\begin{tabular}{|c|c|c|c|c|c|c|c|}
\hline \multirow{2}{*}{ Província } & \multirow{2}{*}{ Intentada } & \multicolumn{2}{|c|}{ Verificada } & \multicolumn{2}{|c|}{ A Revelia } & \multicolumn{2}{|c|}{ No Juízo } \\
\hline & & $\mathbf{N}$ & $\%$ & $\mathbf{N}$ & $\%$ & $\mathbf{N}$ & $\%$ \\
\hline Corte & 2.927 & 565 & 19 & 1.605 & 55 & 757 & 26 \\
\hline Espírito Santo $^{3}$ & 154 & 52 & 34 & 46 & 30 & 56 & 36 \\
\hline Rio Grande do Norte ${ }^{4}$ & 199 & 91 & 46 & 34 & 17 & 74 & 37 \\
\hline Goiás & 208 & 115 & 55 & 40 & 19 & 50 & 24 \\
\hline Mato Grosso ${ }^{5}$ & 62 & 35 & 56 & 17 & 27 & 10 & 16 \\
\hline São Paulo ${ }^{6}$ & 2.953 & 1.218 & 41 & 1.187 & 40 & 548 & 19 \\
\hline Santa Catarina $^{7}$ & 467 & 246 & 53 & 117 & 25 & 104 & 22 \\
\hline Alagoas & 105 & 50 & 48 & 26 & 25 & 29 & 28 \\
\hline Piauî $^{8}$ & 2 & 2 & 100 & 0 & 0 & 0 & 0 \\
\hline Sergipe & 56 & 29 & 52 & 14 & 25 & 13 & 23 \\
\hline Pernambuco & 2.466 & 1.298 & 53 & 660 & 27 & 508 & 21 \\
\hline Bahia & 1.229 & 301 & 24 & 639 & 52 & 289 & 24 \\
\hline Rio de Janeiro & 313 & 96 & 31 & 135 & 43 & 82 & 26 \\
\hline Ceará & 472 & 227 & 48 & 129 & 27 & 116 & 25 \\
\hline Total & 11.613 & 4.325 & 37 & 4.649 & 40 & 2.636 & 23 \\
\hline
\end{tabular}

Fonte: Brasil (1857).

dos diversos juizados de paz do país no que tange à conciliação. A taxa média de sucesso alcançou naquele ano a cifra de 37\%, com uma proporção de $23 \%$ de revelia. Descontada esta, a porcentagem de conciliação alcançaria quase $50 \%$. A Tabela 5 reúne todos os dados do Império encontrados nos relatórios dos ministros de Justiça e possui recorte temporal entre 1854 e 1874. Nela, as taxas de conciliação variam entre $24 \%$ e $58 \%$, como se vê:

Apesar de os relatórios do Ministério da Justiça terem edição anual desde 1825, grande parte deles não possui dados sobre conciliação. De fato, somente na segunda metade do século XIX, essas informações são incluídas nesses documentos, mas perduram somente até 1874. Ademais, como mencionado, são mapas incompletos, que não contemplam todas as províncias e muito menos todas as freguesias (para o ano de 1854, por exemplo, só foram incluídos dados da Corte, Amazonas, Pará e Santa Catarina). A separação entre conciliações não verificadas por revelia ou no juízo também não está presente em todos os relatórios e, por isso, não foi fornecida na tabela construída. 
A Conciliação e os Meios Alternativos de Solução de Conflitos no Império...

Tabela 5

Conciliações no Império (1854-1874)

\begin{tabular}{c|cc|cc|c}
\hline \multirow{2}{*}{ Ano } & \multicolumn{2}{|c|}{ Verificadas } & \multicolumn{2}{c|}{ Não Verificadas } & \multirow{2}{*}{ Total } \\
\cline { 2 - 5 } & $\mathbf{N}$ & $\%$ & $\mathbf{N}$ & \% & \\
\hline 1854 & 854 & 24 & 2.775 & 76 & 3.629 \\
1857 & 4.328 & 37 & 7.282 & 63 & $\mathbf{1 1 . 6 1 0}$ \\
1866 & 1.498 & 24 & 4.823 & 76 & $\mathbf{6 . 3 2 1}$ \\
1867 & 2.623 & 29 & 6.444 & 71 & $\mathbf{9 . 0 6 7}$ \\
1869 & 1.686 & 32 & 3.535 & 68 & 5.221 \\
1870 & 2.671 & 29 & 6.548 & 71 & $\mathbf{9 . 2 1 9}$ \\
1871 & 4.656 & 58 & 3.395 & 42 & $\mathbf{8 . 0 5 1}$ \\
1872 & 1.813 & 29 & 4.468 & 71 & $\mathbf{6 . 2 8 1}$ \\
1873 & 2.016 & 30 & 4.690 & 70 & $\mathbf{6 . 7 0 6}$ \\
1874 & 2.776 & 37 & 4.816 & 63 & 7.592 \\
\hline
\end{tabular}

Fonte: Brasil (1854-1874).

Postos os dados, é preciso indagar sobre o conteúdo material dessas estatísticas. Aquelas organizadas pelo governo tinham como ponto de partida o próprio juízo de paz e só começaram a ser realizadas de forma sistemática na segunda metade do século XIX. Eram ofícios, com mapa padrão, sem informações adicionais que não os números solicitados de conciliações intentadas, verificadas, à revelia ou fracassadas. Portanto, não reproduzem o dia a dia dos juízos, o modo como as conciliações eram feitas nem a participação efetiva do magistrado na mediação entre as partes. Tais informações são dificilmente acessíveis, já que, mesmo nos processos, a realização da conciliação era registrada apenas em protocolo ou termo, que seguiam modelos-padrão. Ademais, enquanto seus agentes executores, as impressões dos juízes de paz sobre as mediações que realizavam poderiam ser bastante parciais, no raro caso em que fossem registradas. O cotidiano das conciliações deve assim ser buscado em outro tipo de fonte, como aquela usada no início desta seção. A obra literária constitui excelente documento para analisar os aspectos metajurídicos de institutos legais, já que seu autor é um observador contemporâneo externo ao fenômeno e, ao mesmo tempo, privilegiado, pois possui sensibilidade a minúcias que escapavam dos funcionários da Justiça ou que são por eles camuflados. Não obstante, como já ressaltado, sua análise deve ser feita com cuidado e não ao pé da letra, porquanto os dados informativos são aspectos secundários da obra, ou seja, não consistem em seu objetivo principal de entreter ou extravasar os sentimentos do autor. 


\section{CONCLUSÃO}

Ao longo do texto, procuramos mostrar como a conciliação foi inserida no ordenamento jurídico do Brasil Império e o papel de destaque que desempenhou no direito processual pátrio. Por meio de dados empíricos, jornais e anais do parlamento, mostramos a valoração positiva dada ao instituto, tanto por políticos da cúpula do governo quanto por habitantes dos mais distantes rincões do país, que passaram a usufruir dos benefícios por ele trazidos.

Apesar de incompletas, as estatísticas apresentadas afiguram-se de importantíssimo valor, pois confirmam o papel central da conciliação no funcionamento do Judiciário imperial. Nos dados mais gerais, com cifras entre $24 \%$ e $58 \%$, os apaziguamentos das partes verificados no período mostram que os juízes de paz espalhados pelo Brasil seguiam com razoável sucesso seu papel constitucional de conciliadores.

Ainda se deve observar a recepção positiva não só do instituto da conciliação nos primeiros anos do Império, mas também do titular da atribuição - o juiz de paz. Com o tempo, porém, a magistratura popular enfrentou severas críticas e, a partir do ano de 1834, articularam-se, no parlamento brasileiro, muitas limitações a esses magistrados no âmbito da prevenção dos delitos, reunião de provas, entre outras. Não se lançava a hipótese, porém, de retirar-lhe a função conciliadora, até porque se constituía em mandamento constitucional.

Ainda hoje, segundo a Constituição de 1988, cabe a juízes de paz eleitos a função conciliatória, além daquelas relacionadas com o matrimônio. Infelizmente, a investidura por eleição e o exercício de conciliação por esses magistrados não têm sido respeitados, com raras exceções, pelos estados ou pela União, restando-lhe apenas a função de realizar casamentos. Por outro lado, a experiência imperial, debatida neste texto, serve como importante exemplo para que os preceitos constitucionais citados sejam não apenas observados, como valorizados pelo poder público e pela sociedade civil.

(Recebido para publicação em setembro de 2013)

(Reapresentado em dezembro de 2014)

(Aprovado para publicação em abril de 2015) 


\section{A Conciliação e os Meios Alternativos de Solução de Conflitos no Império...}

\section{NOTAS}

1. Grafava-se embigada. Segundo Fonseca (1856:419), era a forma coloquial de denominar o embate de umbigo com umbigo.

2. Espera receber mercê.

3. Não foram incluídos os mapas das seguintes freguesias: Meaípe, Itabapoana, Cachoeira, Almeida, Viana e Cariacica.

4. Não foram incluídos os mapas das seguintes freguesias: Jundiaí, Touros, Maracajaú, Caissara, São José, Vila de Arez, Santa Cruz, Goyaninha, Santa Ana do Mato, Vargas, Monsoró, São Sebastião, Macau, Príncipe, Acari, Pão dos Ferros, São Miguel, Carauba e Apodi.

5. Não foram incluídos os mapas das seguintes freguesias: Santa Ana da Paranaíba, Miranda e Vila Maria.

6. Não foram incluídos os mapas das seguintes freguesias: Sapé, Boquirá, São José do Paraíba, Caraguatatuba, São Vicente, Juquiá, nossa Senhora do Socorro, Curato do Espírito, São João do Rio Claro, Belem do Descabrado, Curato do Jahú, Curato de São Carlos do Pinhal, do Rio Preto, Franca do Imperador, Nossa Senhora do Carmo, Batatais, Cajuru, São Sebastião da Boa Vista, Batucatu, São João Batista, Indaiatuba e Una.

7. Só foram incluídos os mapas das seguintes freguesias: Nossa Senhora da Graça, Nossa Senhora do Patrocínio e São Sacramento de Itajaí.

8. Só foram incluídos os mapas da comarca da Paraíba. 


\section{REFERÊNCIAS BIBLIOGRÁFICAS}

BRANDÃO NETO, João Marques. (2005), “Juizados Especiais: A Fênix da Justiça Ibero-Brasileira". Boletim Científico ESMPU, ano 4, no 16, pp. 263-277.

CAMPOS, Adriana Pereira. (2011), “Magistratura Leiga no Brasil Independente: A Participação Política Eleitoral", in M. H. Pereira et al. (orgs.), Linguagens e Fronteiras do Poder. Lisboa, ISCTE, pp. 259-273.

; VELLASCO, Ivan. (2011), “Juízes de Paz, Mobilização e Interiorização da Política", in J. M. Carvalho; A. P. Campos (orgs.), Perspectivas da Cidadania no Brasil Império. Rio de Janeiro, Civilização Brasileira, pp. 377-408.

CARNEIRO, Carlos Antônio. (1864), Diretor do Juízo de Paz. Rio de Janeiro, B. L. Garnier.

CLAVERO, Bartolomé. (2007), El Orden de los Poderes: Historia Constituyentes de la Trinidad Constitucional. Madrid, Trotta.

DEMARCHI, Juliana. (2007), Mediação: Proposta de Implementação no Processo Civil Brasileiro, Tese (Doutorado em Direito), Universidade de São Paulo, São Paulo.

FLORY, Thomas. (1981), Judge and Jury in Imperial Brazil, 1808-1871. Austin, University of Texas Press.

FONSECA, José. (1856), Dicionário da Língua Portuguesa. Paris, V J P Aillaud, Monlon e C.

HESPANHA, António Manuel. (1994), As Vésperas do Leviathan. Coimbra, Livraria Almedina.

LENZA, Pedro. (2005), “Reforma do Judiciário. Emenda Constitucional no 45/2004”. Jus Navigandi [online]. Disponível em http://jus.com.br/revista/texto/6463/reformado-judiciario-emenda-constitucional-no-45-2004. Acesso em março de 2013.

LORENCINI, Marco Antônio Garcia Lopes. (2012), Juizados Especiais. Curitiba, IESDE Brasil.

MACEDO, Joaquim Manoel de. (1855), A Carteira de meu Tio. Rio de Janeiro, Dois de Dezembro.

MENDONÇA, José Xavier de Carvalho de. (1889), Tratado Teórico e Prático das Justiças de Paz. Rio de Janeiro, Garnier.

MENEGHIN, Laís; NEVES, Fabiana J. Tamaoki. (2010), “Meios Alternativos de Pacificação de Conflitos: Mediação, Conciliação e Arbitragem". Encontro de Iniciação Científica das Faculdades Integradas Antonio Eufrásio Toledo, vol. 6, № 6.

MOTTA, Kátia Sausen da. (2010), “Do Debate à Lei: A Estruturação do Juiz de Paz na Primeira Metade do Oitocentos". Anais do XIV Encontro Regional de História da ANPUH-Rio: Memória e Patrimônio, Rio de Janeiro, Núcleo de Documentação, História e Memória.

(2013), Juiz de Paz e Cultura Política no Início do Oitocentos (Província do Espírito Santo, 1827-1842). Dissertação (Mestrado em História), Universidade Federal do Espírito Santo, Vitória.

NASCIMENTO, Joelma Aparecida do. (2010), Os "Homens" da Administração e da Justiça no Império: Eleição e Perfil Social dos Juízes de Paz em Mariana. Dissertação (Mestrado em História), Universidade Federal de Juiz de Fora, Juiz de Fora. 
A Conciliação e os Meios Alternativos de Solução de Conflitos no Império...

NEVES, Lúcia Maria Bastos Pereira das. (2003), Corcundas e Constitucionais: A Cultura Política da Independência (1820-1822). Rio de Janeiro, Revan.

PENA, Martins. (1997), O Juiz de Paz da Roça. São Paulo, Publifolha.

RIBAS, Antonio Joaquim. (1879), Consolidação do Processo Civil. Rio de Janeiro, Dias da Silva Junior.

ROBERTO, Giodarno Bruno Soares. (2012), “Antonio Joaquim Ribas: Notas Preliminares sobre Carreira Acadêmica e Produção Bibliográfica", in G. B. S. Roberto (org.), Temas em História do Direito Brasileiro. Belo Horizonte, Initia Via.

RUIZ, Ivan Aparecido; GONÇALVES, Heloísa Alva Cortez. (2011), “Da Conciliação: Uma Forma de Evitar a Jurisdição, pela Via Consensual, por meio de um Processo mais Justo". Revista Jurídica Cesumar - Mestrado, vol. 11, no 1, pp. 53-80.

SALES, José Roberto da Cunha. (1879), Tratado da Praxe Conciliatória. Rio de Janeiro, Nicolao d'Oliveira S.C.

SILVA, João Nepomuceno da. (1864), Sátiras. Rio de Janeiro, Tipografia de Domingos Luiz dos Santos.

SOUZA, Alexandre de Oliveira Bazilio de. (2013), Das Urnas para as Urnas: Juízes de Paze Eleições no Espírito Santo (1871-1889). Saarbrücken, Novas Edições Acadêmicas.

VAINFAS, Ronaldo (org.). (2002), Dicionário do Brasil Imperial (1822-1889). Rio de Janeiro, Objetiva.

VASCONCELlOS, José Marcelino Pereira de. (1862), Atos, Atribuições e Obrigaç̧̃es dos Juízes de Paz. Rio de Janeiro, Eduardo \& Henrique Laemmert.

VELLASCO, Ivan de Andrade. (2003), “O Juiz de Paz e o Código do Processo: Vicissitudes da Justiça Imperial em uma Comarca de Minas Gerais no Século XIX". Justiça História, vol. 3, no 6, pp. 65-96.

VIANNA, Luiz Werneck. (1999), A Judicialização da Política e das Relações Sociais no Brasil. Rio de Janeiro, Revan.

WAGNER JR., Luiz Guilherme da Costa. (2008), Processo Civil. Belo Horizonte, Del Rey.

WATANABE, Kazuo. (2011), “Política Pública do Poder Judiciário Nacional para Tratamento Adequado dos Conflitos de Interesses", in A. C. Peluso; M. A. Richa (orgs.), Conciliação e Mediação: Estruturação da Política Judiciária Nacional. São Paulo, Forense. 


\section{DOCUMENTOS}

ACERVO JUDICIÁRIO. (1830-1899), Base de Dados, Arquivo Nacional.

ATAS DAS CORTES GERAES E EXTRAORDINÁRIAS DA NAÇÃO PORTUGUESA [ACP]. (1823), Arquivo da Assembleia da República de Lisboa.

AURORA FLUMINENSE. (1830), Rio de Janeiro (Hemeroteca da Biblioteca Nacional).

BRASIL. (1854-1874). Relatórios do Ministério da Justiça. Rio de Janeiro, Imprensa Nacional.

(1857), Relatório do Ministério da Justiça. Rio de Janeiro, Imprensa Nacional, p. A-B-54.

Câmara dos Deputados. (1889), Organizações e Programas Ministeriais. Organizado pelo diretor conselheiro barão de Javary. Rio de Janeiro, Imprensa Nacional.

DIÁRIO DO RIO DE JANEIRO [DRJ]. (1837 e 1830), Rio de Janeiro, Hemeroteca da Biblioteca Nacional.

ESTATÍSTICAS DO SUPREMO TRIBUNAL FEDERAL. (2012), Disponível em http: / / www.stf.jus.br/portal/cms/verTexto.asp?servico=estatistica\&pagina= REAIProcessoDistribuido. Acesso em março de 2013.

JUSTIÇA EM NÚMEROS. (2012), Relatório, Conselho Nacional de Justiça. Disponível em http:/ / www.cnj.jus.br/images/pesquisas-judiciarias/Publicacoes/rel_completo_ estadual.pdf. Acesso em março de 2013.

OFÍCIOS DIVERSOS. (1854-1885), Arquivo Público do Estado de São Paulo.

STJ (SUPERIOR TRIBUNAL DE JUSTIÇA). (2012), “Em 2011 Tramitaram no Brasil mais de 90 Milhões de Processos Judiciais". Sala de Notícias. Disponível em http: / /www.stj.jus.br/portal_stj/publicacao/engine.wsp?tmp.area= 398\&tmp.texto=107545. Acesso em março de 2013. 
A Conciliação e os Meios Alternativos de Solução de Conflitos no Império...

\section{RESUMO}

A Conciliação e os Meios Alternativos de Solução de Conflitos no Império Brasileiro

A conciliação é uma modalidade alternativa de solução de conflitos com longa história no ordenamento jurídico brasileiro. Embora prevista desde tempos coloniais, o instituto só ganhou contornos mais próximos dos atuais a partir da Independência do país, quando passou a ser procedimento obrigatório, realizado no então recém-criado juízo de paz. Este artigo analisa a criação legislativa e o funcionamento do instituto no país durante o século XIX, a fim de caracterizar sua relevância para a eficiência da Justiça brasileira. Para isso, foram utilizados como fonte anais do parlamento, livros doutrinários, jornais, textos literários, relatórios de governo, ofícios, além da própria legislação. Concluímos que a conciliação no Império foi responsável pela forte redução no número de processos que tramitavam no Brasil naquele momento, com taxa de acordo que frequentemente passava dos $50 \%$.

Palavras-chave: conciliação; Brasil Império; justiça de paz; solução de conflitos; eficiência da Justiça

\section{ABSTRACT \\ Reconcilement and Alternative Means of Conflict Resolution in the Brazilian Empire}

Reconcilement is an alternative mode of conflict resolution with a long history in the Brazilian judicial system. Although it was already known in colonial times, it only gained similar aspects to the present institute after the country's Independence, when it became a mandatory proceeding, carried out by the justices of the peace, whose office was then recently established. This article analyzes the legislative creation and functioning of this institution in Brazil during the nineteenth century, with the aim of characterizing its relevance for the efficiency of Brazilian Justice. In order to achieve this goal, several sources were used: the annals of parliament, legal doctrine, newspapers, literary texts, official reports and other documents, in addition to the legislation. We concluded that, during the Empire, conciliation was responsible for a great reduction in the number of legal processes pursued in Brazil at that time, with settlement agreement rates that often surpassed fifty percent.

Keywords: conciliation; Brazilian Empire; justices of the peace; dispute resolution; efficiency of Justice 


\section{RÉSUMÉ}

La Conciliation et les Moyens Alternatifs de Résolution des Conflits sous l'Empire

Brésilien

La conciliation est une modalité alternative de résolution des conflits intégrée depuis longtemps au système juridique brésilien. Bien que prévue depuis l'époque coloniale, ce n'est qu'à partir de l'indépendance du pays qu'elle assumera des contours relativement proches de ce qu'elle est aujourd'hui. Elle devint en effet à cette époque une procédure obligatoire que devait mener le juge de paix, une fonction tout récemment créée. Cet article analyse ainsi la création législative et le fonctionnement de cette conciliation au cours du XIXème siècle, afin d'en analyser la pertinence pour l'efficacité de la justice brésilienne. À cette fin, nous avons utilisé comme sources les annales du parlement, des ouvrages de doctrine, des journaux, des textes littéraires, des rapports gouvernementaux, des textes officiels et la législation elle-même. Nous en avons conclu que la conciliation sous l'Empire a permis une forte réduction du nombre des procès menés au Brésil à cette époque, avec des taux de conciliation dépassant le plus souvent les $50 \%$.

Mots-clés: conciliation; Empire brésilien; justice de paix; résolution des conflits; efficacité de la justice

\section{RESUMEN}

\section{La Conciliación y los Medios Alternativos de Resolución de Conflictos en el Imperio Brasileño}

La conciliación es una modalidad alternativa de solución de conflictos con larga trayectoria en el ordenamiento jurídico brasileño. Aunque prevista desde los tiempos coloniales, el instituto sólo ganó una forma semejante a la actual con la independencia del país, cuando pasó ser un procedimiento obligatorio, realizado en el recién creado juicio de paz. Este artículo analiza la creación legislativa y el funcionamiento del instituto en el país durante el siglo XIX, con el objetivo de examinar su relevancia para la eficiencia de la justicia brasileña. Para ello, se han utilizado varios tipos de fuentes: anales parlamentares, libros doctrinarios, periódicos, textos literarios, informes de gobierno y oficios, además de la propia legislación. El texto concluye sugiriendo que la conciliación en el Imperio fue responsable por una fuerte reducción en el número de procesos que tramitaban en Brasil en aquel momento, con tasas de acuerdo que solían superar el $50 \%$ de los casos.

Palabras clave: conciliación; Brasil imperio; justicia de paz; resolución de conflictos; eficiencia de la justicia 